\title{
Absorption capacity of fructose in healthy adults. Comparison with sucrose and its constituent monosaccharides
}

\author{
J J RUMESSEN, AND E GUDMAND-HØYER \\ From the Department of Internal Medicine F, Gentofte University Hospital, Hellerup, Denmark
}

SUMMARY The capacity to absorb fructose in 10 healthy adults was investigated by means of hydrogen breath analysis. Fructose absorption was quantified with lactulose standards. Significant hydrogen production ( $\geq 20 \mathrm{ppm}$ rise of breath hydrogen) was found after challenge with $10 \%$ solutions of $50,37 \cdot 5,25,20$, and $15 \mathrm{~g}$ fructose in eight, seven, five, four and one subjects, respectively. One subject showed malabsorption after a $10 \mathrm{~g}$ dose and possibly also $5 \mathrm{~g}$ fructose. In contrast, no malabsorption could be detected in any of the 10 subjects after ingestion of $100 \mathrm{~g}, 75 \mathrm{~g}$, or $50 \mathrm{~g}$ sucrose or a mixture of $50 \mathrm{~g}$ glucose and $50 \mathrm{~g}$ fructose. After ingestion of mixtures of $50 \mathrm{~g}$ fructose $+25 \mathrm{~g}$ glucose and $50 \mathrm{~g}$ fructose $+12.5 \mathrm{~g}$ glucose malabsorption was present in three and seven subjects, respectively. Symptoms during all challenges were mild, or absent. It is concluded that in the healthy state the absorption capacity of fructose given alone ranges from less than $5 \mathrm{~g}$ to more than $50 \mathrm{~g}$. The absorption capacity of fructose given as sucrose is much higher. Glucose stimulates fructose uptake in a dose dependent fashion. The possible existence of more than one intestinal transport system for fructose is considered. The elucidation of the clinical relevance of the findings is important.

Fructose absorption in man is still poorly understood. Fructose is absorbed at a slower rate than galactose and glucose, ${ }^{1}$ but more efficiently than passively transported sugars. ${ }^{2}$ Fructose is probably not absorbed against a concentration-gradient. ${ }^{3}$ Thus, although the mechanism may still be controversial, fructose absorption in man seems to take place by energy independent facilitated transport. An active carrier mediated mechanism for fructose transport has been found in rat small intestine. ${ }^{45}$ The subject has recently gained new interest as it has been suggested that the absorption capacity of fructose is limited in health, ${ }^{6}$ and that glucose may stimulate fructose absorption in children. ${ }^{7}$

Because systematic studies comparing the total absorption capacity of fructose, sucrose, and fructose/glucose mixtures are not available in the literature, and as malabsorption of fructose may be of clinical relevance as an aetiologic factor in some

Address for correspondence: Dr J J Rumessen, Gentofte University Hospital, Department of Internal Medicine F (Gastroenterology), DK-2900 Hellerup, Denmark.

Received for publication 4 February 1986. cases of otherwise unexplained chronic gastrointestinal distress, ${ }^{8-10}$ we carried out a systematic study of these relationships in healthy adults.

\section{Methods}

SUBJECTS

Ten healthy adults with no evidence of recurrent or present gastrointestinal or pulmonary disease participated in the study. Their ages ranged from 25-51 years, there were seven men and three women.

\section{HYDROGEN BREATH TESTS}

Breath hydrogen excretion was measured at intervals as end-expiratory hydrogen concentrations in ppm. Duplicate samples of expired air were collected in $20 \mathrm{ml}$ plastic syringes $\left(\right.$ Once $\left.^{\circledR}\right)$ at intervals of 15-30 minutes for three or four hours after ingestion of the test solution, and three times immediately before ingestion. Samples were immediately analysed on a GMI (Gas Measurements Instruments Ltd, Renfrew, Scotland) exhaled hydrogen monitor with a sensitivity of $2 \mathrm{ppm}$ and an 
accuracy of $+1-2 \%$. The subjects fasted for at least nine hours (overnight) before the study, which took place between $8 \mathrm{am}$ and $1 \mathrm{pm}$. During the study period sleeping and smoking was not allowed, and the subjects were non-ambulant. None was taking antibiotics, acetylsalicylic acid, laxatives, or other medication.

Before the study, the subjects were selected on the basis of their ability to generate $a \geq 20 \mathrm{ppm}$ rise in breath hydrogen subsequent to ingestion of $20 \mathrm{~g}$ lactulose as a $20 \%$ solution. In subsequent studies a rise in breath hydrogen of $\geq 20 \mathrm{ppm}$ above the lowest previous values ${ }^{11}$ was thus considered indicative of significant malabsorption. Initial, transient hydrogen peaks (drop off to baseline within the first 60-90 min.) were disregarded. ${ }^{12} 13$

\section{TEST SOLUTIONS}

All subjects were tested on a single blind basis with the sugar solutions shown in Table 1 given with at least two days intervals between them. The fructose

Table 1 Sugar solutions ingested by all the subjects

\begin{tabular}{clll}
\hline Solute & Weight & Volume & Concentration \\
\hline Sucrose & $100 \mathrm{~g}$ & $500 \mathrm{ml}$ & $20 \%$ \\
- & $75 \mathrm{~g}$ & $375 \mathrm{ml}$ & - \\
- & $50 \mathrm{~g}$ & $250 \mathrm{ml}$ & - \\
Fructose & $50 \mathrm{~g}$ & $500 \mathrm{ml}$ & $10 \%$ \\
- & $37.5 \mathrm{~g}$ & $375 \mathrm{ml}$ & - \\
- & $25 \mathrm{~g}$ & $250 \mathrm{ml}$ & - \\
- & $15 \mathrm{~g}$ & $150 \mathrm{ml}$ & - \\
Fructose & $50 \mathrm{~g}+50 \mathrm{~g}$ & $500 \mathrm{ml}$ & $10 \%+10 \%$ \\
+ Glucose & $50 \mathrm{~g}+25 \mathrm{~g}$ & - & $10 \%+5 \%$ \\
& $50 \mathrm{~g}+12.5 \mathrm{~g}$ & - & $10 \%+2 \cdot 5 \%$ \\
Glucose & $50 \mathrm{~g}$ & $500 \mathrm{ml}$ & $10 \%$ \\
\hline
\end{tabular}

concentration was kept constant at $10 \%(550 \mathrm{mM})$. The temperature of the solutions was in all instances approx. $20^{\circ} \mathrm{C}$ (room-temperature).

The conditions of the study only allowed the sucrose solutions and the three large doses of fructose to be given in random order. Five of the subjects were further challenged with $20 \mathrm{~g}$ fructose as at $10 \%$ solutions, and one subject incapable of completely absorbing $15 \mathrm{~g}$ fructose was challenged with $10 \mathrm{~g}$ and $5 \mathrm{~g}$ as $10 \%$ solutions. Hydrogen excretion after ingestion of $100 \mathrm{~g}$ sucrose and the mixture of $50 \mathrm{~g}$ fructose plus $50 \mathrm{~g}$ glucose was studied for four hours to assure complete gastric emptying of the test substances. ${ }^{14}{ }^{15}$ At the end of the study, all subjects were rechallenged with $50 \mathrm{~g}$ fructose as a $10 \%$ solution.

\section{SYMPTOM SCORES}

During all studies the subjects were asked to register all complaints of abdominal distension, rumbling, flatulence, abdominal pain, diarrhoea, or other side effects and to grade each individual symptom into mild, moderate, or severe. The subjects were asked to note any symptom during the 24 hours after each sugar challenge and report on next occasion. Only symptoms quantitatively or qualitatively different from symptoms recorded during the half an hour before challenge were considered.

\section{ETHICS}

Informed written consent was obtained from all subjects before their participation in the study. The study was carried out in accordance with the Helsinki Declaration II, and the study protocol was approved by the Copenhagen County Medical Ethics Committee.

CALCULATIONS AND EXPRESSION OF RESULTS The results were expressed as maximal (peak)

Table 2 Absorption of fructose in gram ( $g$ ) as calculated by means of the lactulose standards in all the subjects ( $n=10)$. The calculated absorbed dose is equal to the given dose if breath hydrogen production was not significant $(<20$ ppm rise)

\begin{tabular}{|c|c|c|c|c|c|c|c|c|}
\hline Subject & $\begin{array}{l}\text { Dose } \\
50 \mathrm{gF}\end{array}$ & $37 I / 2 g F$ & $25 g F$ & $20 \mathrm{gF}$ & $15 g F$ & $50 \mathrm{gF}+50 \mathrm{gG}$ & $50 g F+25 g G$ & $\begin{array}{l}50 \mathrm{gF}+ \\
121 / 2 \mathrm{gG}\end{array}$ \\
\hline $\mathbf{a}$ & $11 \mathrm{~g}$ & $6 \mathrm{~g}^{*}$ & $0 \mathrm{~g}$ & $0 \mathrm{~g}$ & $0 \mathrm{~g}$ & $50 \mathrm{~g}$ & $22 \mathrm{~g}$ & $17 \mathrm{~g}$ \\
\hline b & $26 \mathrm{~g}^{*}$ & $25 \mathrm{~g}$ & $17 \mathrm{~g}$ & $12 \mathrm{~g}$ & $15 \mathrm{~g}$ & $50 \mathrm{~g}$ & $50 \mathrm{~g}$ & $32 \mathrm{~g}$ \\
\hline c & $21 \mathrm{~g}$ & $24 \mathrm{~g}$ & $20 \mathrm{~g}$ & $9 \mathrm{~g}$ & $15 \mathrm{~g}$ & $50 \mathrm{~g}$ & $30 \mathrm{~g}$ & $27 \mathrm{~g}$ \\
\hline d & $29 \mathrm{~g}^{*}$ & $23 \mathrm{~g}$ & $17 \mathrm{~g}$ & $14 \mathrm{~g}$ & $15 \mathrm{~g}$ & $50 \mathrm{~g}^{*}$ & $33 \mathrm{~g}^{*}$ & $35 \mathrm{~g}^{*}$ \\
\hline e & $38 \mathrm{~g}$ & $29 \mathrm{~g}$ & $21 \mathrm{~g}$ & $20 \mathrm{~g}$ & $15 \mathrm{~g}$ & $50 \mathrm{~g}^{*}$ & $50 \mathrm{~g}$ & $43 \mathrm{~g}$ \\
\hline f & $37 \mathrm{~g}^{*}$ & $25 \mathrm{~g}$ & $25 \mathrm{~g}$ & ND & $15 \mathrm{~g}$ & $50 \mathrm{~g}$ & $50 \mathrm{~g}$ & $50 \mathrm{~g}$ \\
\hline g & $46 \mathrm{~g}$ & $30 \mathrm{~g}$ & $25 \mathrm{~g}$ & ND & $15 \mathrm{~g}$ & $50 \mathrm{~g}$ & $50 \mathrm{~g}$ & $46 \mathrm{~g}$ \\
\hline h & $34 \mathrm{~g}$ & $371 / 2 \mathrm{~g}$ & $25 \mathrm{~g}$ & ND & $15 \mathrm{~g}$ & $50 \mathrm{~g}^{*}$ & $50 \mathrm{~g}$ & $36 \mathrm{~g}^{*}$ \\
\hline $\mathrm{i}$ & $50 \mathrm{~g}$ & $371 / 2 \mathrm{~g}$ & $25 \mathrm{~g}$ & ND & $15 \mathrm{~g}$ & $50 \mathrm{~g}^{*}$ & $50 \mathrm{~g}$ & $50 \mathrm{~g}$ \\
\hline j & $50 \mathrm{~g}$ & $371 / 2 \mathrm{~g}$ & $25 \mathrm{~g}$ & ND & $15 \mathrm{~g}$ & $50 \mathrm{~g}^{*}$ & $50 \mathrm{~g}$ & $50 \mathrm{~g}$ \\
\hline
\end{tabular}

ND: Not determined. F: fructose. G: glucose.

${ }^{*}$ Mild flatulence, abdominal rumbling or distension during or after challenge. 
values in breath hydrogen-concentration (ppm) during the study period with subtraction of the lowest previous values (maximal increase, mean of duplicate samples). ${ }^{16}$ The semiquantitative calculations of fructose malabsorption were extrapolated from the areas under the curves (AUC's) with significant breath hydrogen production $(\geq 20 \mathrm{ppm})$, and AUC's obtained from the challenge with $20 \mathrm{~g}$ lactulose ${ }^{17}{ }^{18}$ Areas under the curves were calculated according to the trapezoidal rule, and expressed in arbitrary units $(\mathrm{ppm} \times \mathrm{min})$. In all calculations only the AUC's in the initial 90 minutes of the hydrogen-rise were determined.

Statistical evaluation was done non-parametrically by use of the Mann-Whitney rank sum test. A significance level of 0.05 was used.

\section{Results}

\section{ABSORPTION OF FRUCTOSE}

A significant malabsorption $(\geq 20 \mathrm{ppm}$ rise of breath- $\mathrm{H}_{2}$ ) was present subsequent to challenge with fructose doses of 50,37, 5, 25, 20, 15 and $10 \mathrm{~g}$ in eight, seven, five, four, one, and one subjects, respectively (Fig. 1 and Table 2). A single person (a) with significant $\mathrm{H}_{2}$-production by 15 and $10 \mathrm{~g}$ challenge showed a sustained but $<20 \mathrm{ppm}$ rise after $5 \mathrm{~g}$ fructose (Fig. 2). In this person hydrogen excretion (AUC) subsequent to $20 \mathrm{~g}$ lactulose was equal to hydrogen excretion subsequent to $20 \mathrm{~g}$ and $25 \mathrm{~g}$ fructose (Fig. 2). It is noteworthy that gastrointestinal symptoms during and after the challenges were mild or absent (Table 2). No symptoms were recorded subsequent to doses of 5 to $25 \mathrm{~g}$, and none experienced diarrhoea. From the individual lactulose standards the amount of malabsorbed sugar was calculated in all breath tests, and the corresponding absorbed fractions are shown in Table 2. Both these data and the direct measures of $\mathrm{H}_{2}$-production show that the total absorption capacity of fructose given as a $10 \%$ solution varies from less than $5 \mathrm{~g}$ to more than $50 \mathrm{~g}$ in healthy adults. As many as $50 \%$ of the subjects malabsorb $25 \mathrm{~g}$. It is further seen that the absorption capacity of fructose is dose dependent, as a greater absolute amount (but in some apparently a smaller percentage) is absorbed with increasing challenge dose. It should be noted that the smallest calculated absorbed amounts of fructose correspond fairly closely to the largest fructose doses which give no significant rise in breath- $\mathrm{H}_{2}$ by direct measure and therefore are completely absorbed. Thus there is no discrepancy between these two methods of estimating the limits of fructose absorption capacity. It is remarkable that one subject (a) does not seem to absorb fructose at all, at least when given in doses up to $25 \mathrm{~g}$. This subject reported mild rumbling during challenge with $37.5 \mathrm{~g}$, and experienced no symptoms with other doses.

At the end of the study all subjects were rechallenged with $50 \mathrm{~g}$ fructose and again, in eight of 10 malabsorption was present. Seven of these were the same who showed significant $\mathbf{H}_{2}$-production in the first challenge. Two other subjects had an increase of $\mathrm{H}_{2}$-excretion during both challenges but in only one of the tests $\geq 20 \mathrm{ppm}$. There was a trend towards higher $\mathrm{H}_{2}$-excretion during the second challenge, but the difference was not significant
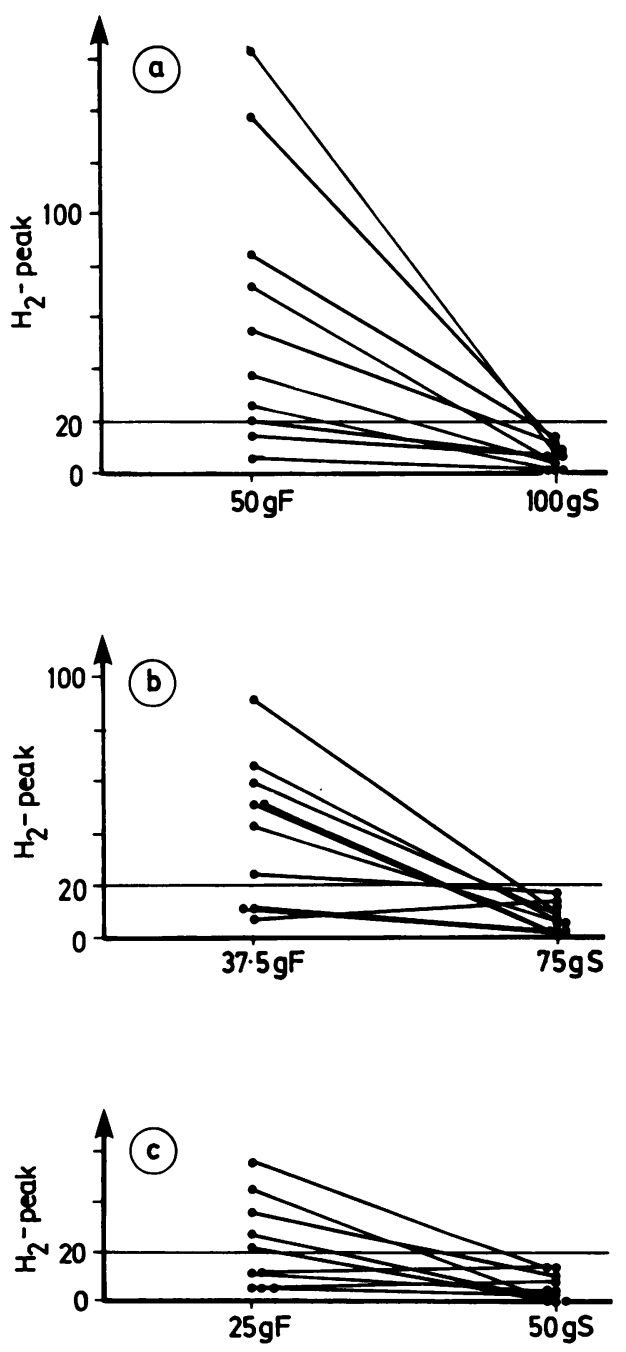

Fig. 1 Absorption of fructose $(F)$ given in different doses $(a-c)$ either as the pure monosaccharide or equivalent amounts given as sucrose (S). The hydrogen production is expressed as maximal increases during 3 hour challenges and 4 hours for $100 \mathrm{~g}$ sucrose. 
$(p>0 \cdot 10)$. There was no relationship between age, sex, or body weight and fructose absorption capacity in this study.

\section{ABSORPTION OF SUCROSE}

None of the subjects showed significant malabsorption at any dose of sucrose given as $20 \%$ solutions. The difference between the absorption capacity of fructose given as sucrose and fructose alone is striking (Figs 1 and 2). The difference between the maximal increases shown in Fig. 1 is highly significant at all doses studied $(\mathrm{p}<0 \cdot 01)$. Although significant ( $\geq 20 \mathrm{ppm}$ ) malabsorption was never seen, the peak hydrogen production after ingestion of $100 \mathrm{~g}$ sucrose was larger compared with the peak hydrogen production after ingestion of $50 \mathrm{~g}$ glucose
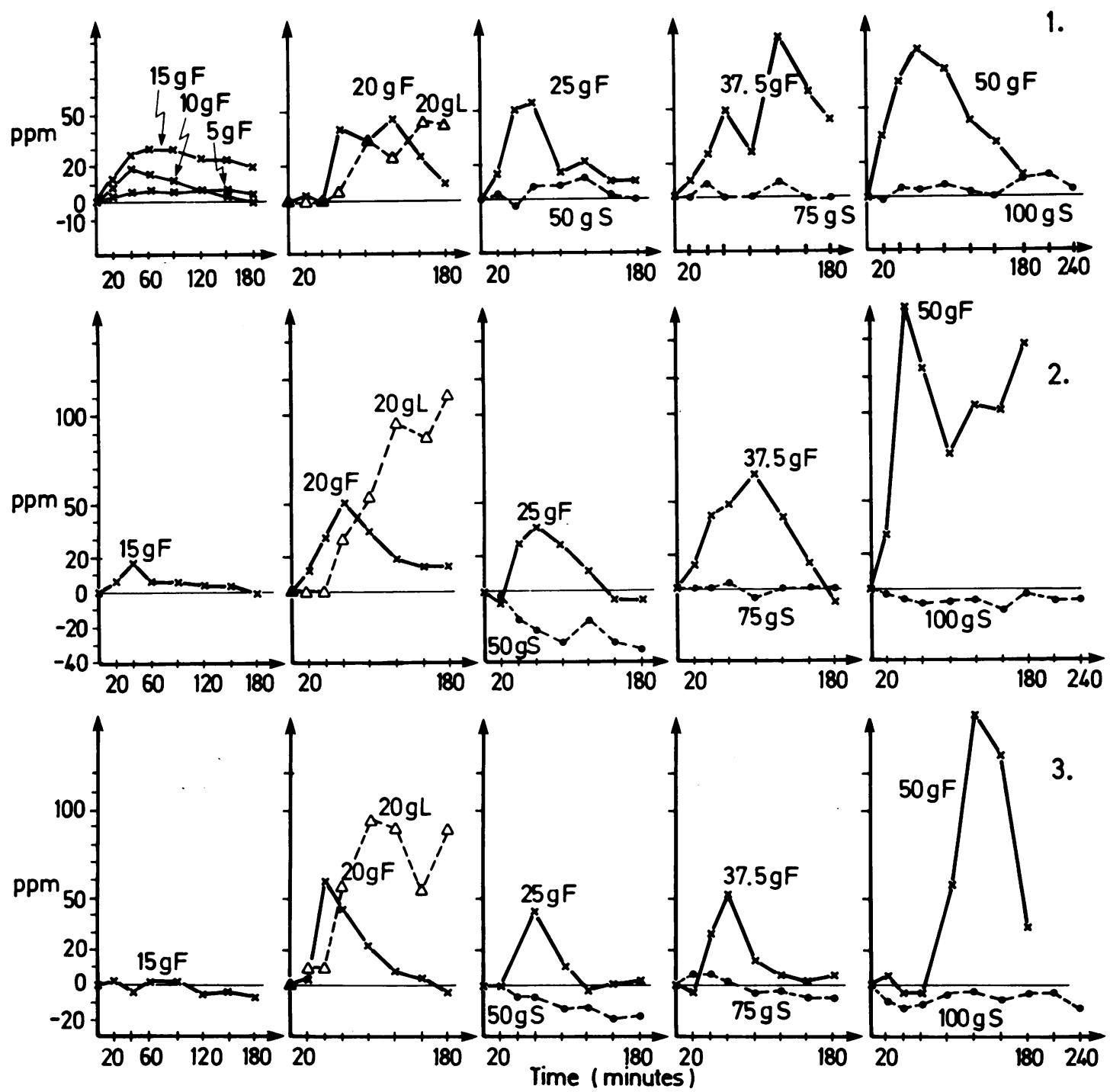

Fig. 2 This Figure shows the complete curves of breath test with fructose ( $F$, crosses and unbroken lines), sucrose $(S$, dots and stipled lines), and $20 \mathrm{~g}$ lactulose ( $L$, triangles and stipled lines) in 3 healthy persons (no. 1-3, correspond to a, $b$ and $c$ in Table 2), incapable of completely absorbing $20 \mathrm{~g}$ fructose. Hydrogen production (ppm) is expressed as absolute concentrations minus base-line (time 0 ) concentrations to obtain the same starting point. Hydrogen excretion after $20 \mathrm{~g}$ lactulose has been shown in the same diagram as $20 \mathrm{~g}$ fructose. 
$(\mathrm{p}<0.02)$ (data not shown) suggesting a minor malabsorption of sucrose or its split products. No difference in hydrogen production was detected between the $50 \mathrm{~g}$ and the $100 \mathrm{~g}$ sucrose challenges $(p>0 \cdot 10)$. Three subjects $(c, d, f)$ experienced mild flatulence and distension with $75 \mathrm{~g}$ sucrose, but no symptoms with 50 or $100 \mathrm{~g}$. One subject $(\mathrm{g})$ reported mild borborygmi with $100 \mathrm{~g}$ sucrose.

\section{EFFECT OF ADDING GLUCOSE}

It is readily apparent from Fig. 3 and Table 2 that the absorption capacity of fructose was greatly
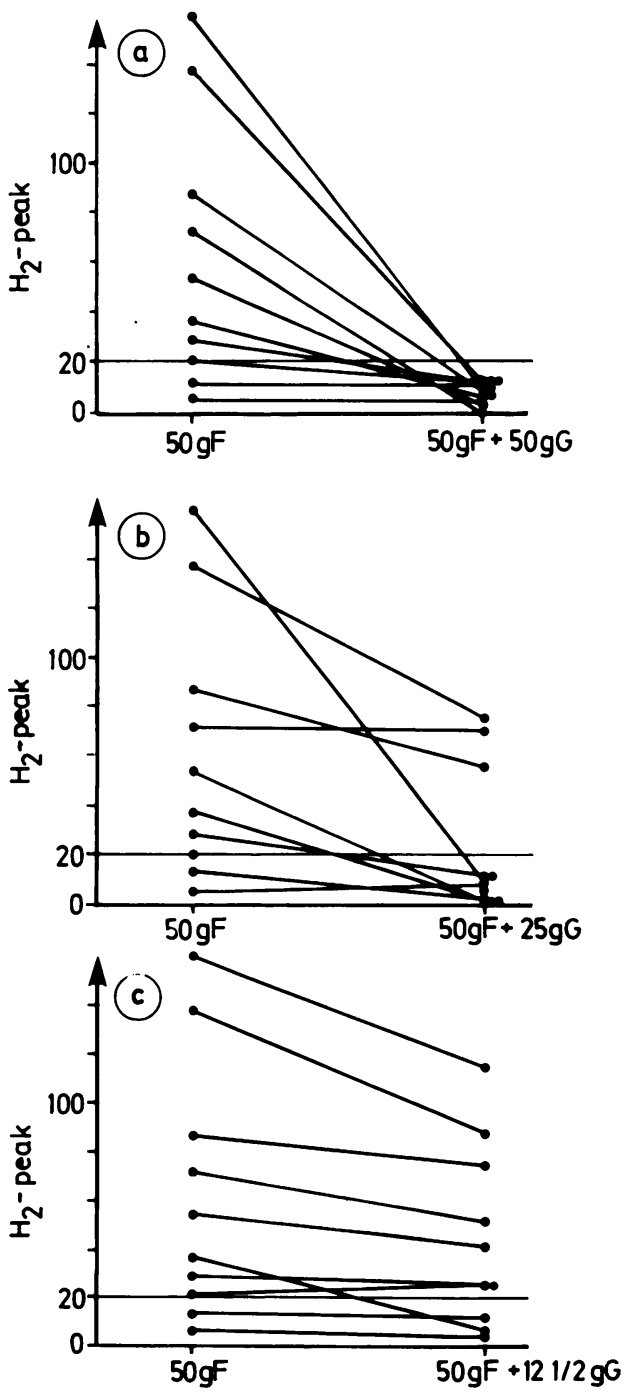

Fig. 3 Effect on fructose malabsorption expressed as maximal increase of hydrogen production of adding different amounts of glucose $(G)$ to the fructose $(F)$ solution. enhanced by the addition of glucose to the mixture in a dose dependent fashion. The greatest effect was seen with equivalent amounts of fructose and glucose, whereas an increasing fraction was malabsorbed as the amount of glucose added was diminished. The differences between the maximal $\mathrm{H}_{2}$ increases in Fig. 3, a and b are highly significant $(p<0.01$ and $p<0.02$ respectively). There was no statistical difference between the $\mathrm{H}_{2}$-peaks subsequent to ingestion of $50 \mathrm{~g}$ fructose $+12.5 \mathrm{~g}$ glucose and $37.5 \mathrm{~g}$ fructose, and similarly there was no difference between hydrogen-peaks obtained with mixtures of $50 \mathrm{~g}$ fructose $+25 \mathrm{~g}$ glucose and $25 \mathrm{~g}$ fructose. Although not statistically significant if hydrogen-peaks are compared ( $p>0 \cdot 10)$ (Fig. 3), it is suggested from Table 2 that fructose is more effectively absorbed in mixtures containing $50 \mathrm{~g}$ fructose $+12.5 \mathrm{~g}$ glucose compared with solutions of $50 \mathrm{~g}$ fructose alone. It was further noted that there was no statistical difference between the hydrogen peaks (all $<20 \mathrm{ppm}$ ) after ingestion of $100 \mathrm{~g}$ sucrose or $50 \mathrm{~g}$ glucose $+50 \mathrm{~g}$ fructose $(\mathrm{p}>0 \cdot 10)$, and thus there was no measurable effect of sucrose hydrolysis. Although no $\mathrm{H}_{2}$-peaks were observed during this study, as many as five subjects reported mild rumbling or mild flatulence subsequent to challenge with $50 \mathrm{~g}$ glucose $+50 \mathrm{~g}$ fructose (Table 2).

\section{GLUCOSE}

None of the subjects showed any significant rise in hydrogen production subsequent to ingestion of $50 \mathrm{~g}$ glucose as a $10 \%$ solution. A small $(<20 \mathrm{ppm})$ initial transient rise of breath hydrogen was seen in two persons. None experienced gastrointestinal symptoms either during or after challenge.

\section{Discussion}

In the present study we have shown that in the healthy state, large individual variations exist in the absorption capacity of fructose, and that the total absorption capacity is even lower than previously believed. ${ }^{6}$ Some healthy individuals may fail to absorb as little as a $5 \mathrm{~g}$ dose.

Furthermore, we have shown that ingestion of fructose as sucrose does not result in appreciable malabsorption and that the addition of glucose to fructose solutions promote fructose absorption in a dose dependent manner. Thus, it seems that malabsorption of fructose in fructose+glucose mixtures is only measurable if fructose is present in excess of glucose. It is now apparent that fructose malabsorption may be considered a normal phenomenon in the healthy state, in analogy with malabsorption of wheat starch ${ }^{19} 20$ and up to $30-40 \mathrm{~g}$ fructose may be malabsorbed without causing significant abdominal 
discomfort in the healthy state. The quantitative assessments of fructose malabsorption in the present study seem valid, as there was a good correspondence between the calculated absorbed amounts of fructose, and the direct hydrogen breath analysis of similar fructose doses (Table 2).

The validity of using lactulose standards for quantitative measurements of carbohydrate malabsorption based on total hydrogen excretion has been clearly shown by Bond and Levitt. ${ }^{17}{ }^{18}$ Read et al ${ }^{13}$ on the other hand have suggested that the magnitude and the timing of the peak increase in breath hydrogen is dependent on ileal emptying rates of the sugars tested. In the present study we have used areas under the hydrogen excretion curves (AUC's) for comparison. Assuming a constant rate of ventilation (which is realistic), it is reasonable to assume that the individual AUC's are very closely correlated to total hydrogen production. It is somewhat puzzling that some of the subjects experienced abdominal symptoms after ingestion of sucrose or fructose-glucose mixtures without biochemical evidence of malabsorption. This may reflect a nonspecific response to the ingestion of a large volume, a somewhat unphysiological meal. The findings stresses the importance of controlled, blind provocation.

The low absorption capacity of fructose given as the monosaccharide contrasts sharply with our finding of a very high absorption capacity of fructose ingested as sucrose. Studies using perfusion techniques have also suggested that sucrose is very efficiently absorbed. ${ }^{21}$ This may either suggest an effect of the presence of glucose or of the process of hydrolysis or both. Earlier perfusion studies have shown that absorption rates of fructose from mixtures of equivalent amounts of fructose and glucose are similar to absorption rates of fructose from a corresponding amount of sucrose. ${ }^{22} 23$ This is in accordance with our findings which strongly suggests that the presence of glucose is the crucial point.

Holdsworth and Dawson ${ }^{24}$ first suggested that fructose absorption in man was stimulated by the presence of glucose. The evidence obtained from animal studies is conflicting on this particular point. ${ }^{52-27}$ In the present study we have found a striking effect of glucose increasing the total fructose absorption capacity in adults. It cannot be ruled out that this phenomenon is at least in part related to the development of high luminal fructose concentrations brought about by glucose stimulated water absorption. It seems likely, however, that a more specific mechanism is involved. Our findings suggest that also in the human intestine a $\mathrm{Na}^{+}-$independent hydrolase-related transport system for glucose and fructose ${ }^{28}$ operate to facilitate the absorption of fructose given as sucrose, which is probably also activated by the co-presence of free glucose. The latter is compatible with the findings of Gray et $a l^{22}$ and $\mathrm{Cook}^{23}$ that there is no difference between the absorption of sucrose and its monosaccharides in man. We suggest, therefore, that two separate mechanisms take part in the absorption of fructose. One mechanism could involve glucose independent facilitated transport ${ }^{29}$ and another glucose dependent fructose cotransport, which would be additive to the transport of a saturating level of free fructose. In light of the present findings in healthy adults of a high incidence of malabsorption of even small amounts of free fructose, a glucose stimulated fructose uptake could have been advantageous at a time when a great deal of the daily food intake consisted of fruit and berries, in which fructose and glucose is abundant ${ }^{30}$ and thus prevent malabsorption. This would impart a functional significance on the hydrolase-related transport system which has been missing. ${ }^{31}$ To our knowledge, the obvious possibility that fructose might promote glucose absorption above a certain saturating level has not been investigated, but if true, the above speculations would be supported.

The presence of two separate mechanisms of fructose uptake is in keeping with the finding that children with glucose-galactose malabsorption compared with healthy children have unimpaired absorption of fructose given as the monosaccharide,,$^{32}$ but implies that children with this disease may have less efficient absorption of fructose given as sucrose, compared with healthy children. The latter has not been investigated.

The clinical implications of our findings are that the presence of malabsorption of a small dose of free fructose in a patient with abdominal disease cannot be considered pathological, but on the other hand that malabsorption of fructose from a normal diet could induce chronic abdominal discomfort in certain sensitive individuals. The latter has already been inferred from case reports and uncontrolled studies of children and adults. ${ }^{8-10}$ It is possible that different clinical entities of fructose malabsorption exist. The patients described by Schneider et $a l^{8}$ and Barnes et $\mathbf{l}^{10}$ did not tolerate fructose either as the monosaccharide or given as sucrose despite the absence of hyposucrasia. The patients described by Andersson et al ${ }^{9}$ were not challenged with sucrose. A transient fructose malabsorption has been described in infants and the phenomenon may be related to bacterial overgrowth of the small intestine ${ }^{33}$ Patients with abdominal distress caused by fructose malabsorption but with complete absorption of sucrose have not been described. A selective lack or an early saturation of the glucose 
independent fructose uptake mechanism will only be clinically apparent if an adequate daily intake of free fructose is accomplished. This may be of particular relevance for the use of fructose as a commercial or nutritive sweetener as in the dietary management of diabetes mellitus. Furthermore, it seems likely that the lower glycaemic effect of fructose as compared with glucose ${ }^{34}$ may be partly due to malabsorption of fructose.

It is possible that the individual sensitivity to a given malabsorbed dose of fructose may be the discriminative factor between healthy subjects and patients with chronic abdominal distress. This suggestion receives support from the finding of great individual sensitivities to lactose malabsorption. ${ }^{35}$ It seems highly relevant to further explore the importance of the above findings in a clinical setting.

The technical assistance of $G$ Kokholm, Executive Scientist, MSc, Radiometer A/S, is gratefully acknowledged. The authors also thank Isa Staack, Lotte Meng Hansen, and Gitte Bischoff for undertaking the breath tests, and Lene Krogh for secretarial assistance.

\section{References}

1 Groen J. The absorption of hexoses from the upper part of the small intestine in man. J Clin Invest 1937; 16: $245-55$.

2 Holdsworth CD, Dawson AM. Absorption of fructose in man. Proc Soc Exp Biol Med 1965; 118: 142-5.

3 White LW, Landau BR. Sugar transport and fructose metabolism in human intestine in vitro. J Clin Invest 1965; 44: 1200-13.

4 Gracey M, Burke V, Oshin A. Active intestinal transport of D-fructose. Biochim Biophys Acta 1972; 266: 397-406.

5 Macrae AR, Neudoerffer TS. Support for the existence of an active transport mechanism of fructose in the rat. Biochim Biophys Acta 1972; 288: 137-44.

6 Ravich WJ, Bayless TM, Thomas M. Fructose: Incomplete intestinal absorption in humans. Gastroenterology 1983; 84: 26-9.

7 Kneepkens CMF, Vonk RJ, Fernandes J. Incomplete intestinal absorption of fructose. Arch Dis Child 1984; 59: 735-8.

8 Schneider F, Günther O. Malabsorption-Syndrom infolge laktasemangels kombiniert mit fruktoseunverträglichkeit. Dtsch Zeit Verdauung Stoffwechselkrankh 1969; 29: 393-400.

9 Andersson DEH, Nygren A. Four cases of longstanding diarrhoea and colic pains cured by fructosefree diet - A pathogenetic discussion. Acta Med Scand 1978; 203: 87-92.

10 Barnes G, McKellar W, Lawrance S. Detection of fructose malabsorption by breath hydrogen test in a child with diarrhea. J Pediatr 1983; 103: 575-7.
11 Metz G, Jenkins DJA, Peters TJ, Newman A, Blendis LM. Breath hydrogen as a diagnostic method for hypolactasia. Lancet 1975; 1: 1155-7.

12 Kotler DP, Holt PR, Rosenzweig NS. Modification of the breath hydrogen test: Increased sensitivity for detection of carbohydrate malabsorption. J Lab Clin Med 1982; 100: 798-805.

13 Read NW, Al-Janabi MN, Bates TE et al. Interpretation of the breath hydrogen profile obtained after ingesting a solid meal containing unabsorbable carbohydrate. Gut 1985; 26: 834-42.

14 Elias E, Gibson GJ, Greenwood LF, Hunt JN, Tripp $\mathrm{JH}$. The slowing of gastric emptying by monosaccharides and disaccharides in test meals. J Physiol 1968; 194: 317-26.

15 Brener W, Hendrix TR, McHugh PR. Regulation of the gastric emptying of glucose. Gastroenterology 1983; 85: 76-82.

16 Barr RG, Watkins JB, Perman JA. Mucosal function and breath hydrogen excretion: Comparative studies in the clinical evaluation of children with nonspecific abdominal complaints. Pediatrics 1981; 68: 526-33.

17 Bond JH, Levitt MD. Use of pulmonary hydrogen $\left(\mathrm{H}_{2}\right)$ measurements to quantitate carbohydrate absorption. $J$ Clin Invest 1972; 51: 1219-25.

18 Bond JH, Levitt MD. Quantitative measurement of lactose absorption. Gastroenterology 1976; 70: 105862.

19 Calloway DH, Chenoweth WL. Utilization of nutrients in milk- and wheat-based diets by men with adequate and reduced abilities to absorb lactose. I. Energy and nitrogen. Am J Clin Nutr 1973; 26: 929-51.

20 Anderson IH, Levine AS, Levitt MD. Incomplete absorption of the carbohydrate in all-purpose wheat flour. $N$ Engl J Med 1981; 304: 891-2.

21 Gray GM, Ingelfinger FJ. Intestinal absorption of sucrose in man. The site of hydrolysis and absorption. $J$ Clin Invest 1965; 44: 390-8.

22 Gray GM, Ingelfinger FJ. Intestinal absorption of sucrose in man: Interrelation of hydrolysis and monosaccaride product absorption. J Clin Invest 1966; 45: 388-98.

23 Cook GC. Comparison of the absorption and metabolic products of sucrose and its monosaccharides in man. Clin Sci 1970; 38: 687-97.

24 Holdsworth CD, Dawson AM. The absorption of monosaccharides in man. Clin Sci 1964; 27: 371-9.

25 Schultz SG, Strecker CK. Fructose influx across the brush border of rabbit ileum. Biochim Biophys Acta 1970; 211: 586-8.

26 Milla PJ, Muller DPR, Harries JT. Glucose stimulates fructose absorption: clinical implications in health and disease. Arch Dis Child 1977; 52: 429.

27 Holloway PAH, Parsons DS. Absorption and metabolism of fructose by rat jejunum. Biochem $J$ 1984; 222: $57-64$.

28 Ramaswamy K, Malathi P, Caspary WF, Crane RK. Studies on the transport of glucose from disaccharides by hamster small intestine in vitro. II. Characteristics of the disaccharidase-related transport system. Biochem Biophys Acta 1974; 345: 39-48. 
29 Ravich WJ, Bayless TM. Carbohydrate absorption and malabsorption. Clin Gastroenterol 1983; 12: 335-56.

30 Hardinge MG, Swarner JB, Crooks H. Carbohydrates in foods. J Am Diet Assoc 1965; 46: 197-204.

31 Crane RK. 15 years of struggle with the brush border. In: Csaky TZ, ed. Intestinal absorption and malabsorption. Raven Press: New York, 1975: 127-42.

32 Lindquist B, Meeuwisse GW. Intestinal transport of monosaccharides in generalized and selective malabsorption. Acta Paediatr 1963; suppl. 146: 110-15.
33 Gracey M, Burke V, Anderson GM. Association of monosaccharide malabsorption with abnormal smallintestinal flora. Lancet 1969; 2: 384-5.

34 Crapo P, Kolterman OG, Olefsky JM. Effects of oral fructose in normal, diabetic, and impaired glucose tolerance subjects. Diabetes Care 1980; 3: 575-82.

35 Gudmand-Høyer E, Simony K. Individual sensitivity to lactose malabsorption. Am J Dig Dis 1977; 22: $177-81$. 